\title{
15. Multiple Benefits through the Life Cycle of the Basin Plan
}

\author{
Darla Hatton MacDonald, Rosalind Bark, Dustin Garrick, \\ Onil Banerjee, Jeff Connor, Mark Morrison
}

\section{Introduction}

The objectives of the new water-sharing plan for the Murray-Darling Basin Plan are set out in the Water Act 2007 (Cwlth); cardinal among these objectives is the maximisation of economic, social and environmental outcomes for the Australian community (Water Act 2007, ss. 3[c] and [d][iii], s. 20[d]). Meeting this objective requires an extensive process of biophysical modelling and economic analysis of the costs and benefits associated with resetting the balance among multiple water users, including the environment. Maximising net benefits applies to plan development where implementation can be thought of as a two-stage process: a) establishing long-term sustainable diversion limits (SDLs) that set the overall balance of water available for the environment versus consumptive uses; b) developing basin-level plans for environmental watering, water quality, accreditation, and water-trading rules. Included in this is the design of mechanisms and incentives to incorporate basin-wide targets and goals into State water-sharing plans and operational delivery mechanisms.

The Guide to the proposed Basin Plan (MDBA 2010), released on 8 October 2010, could be interpreted as the first stage in this process of establishing a feasible range of long-term reductions in diversions. The framework for assessing the balance among consumptive users and the environment in the Guide involves weighing the cost to irrigated agriculture in terms of forgone production, including the potential flow-on impacts to employment and irrigation-dependent communities, and a comparison of these with the potential benefits derived from ecological responses to various environmental waterallocation scenarios. Ecological modelling has determined that over the long term the amount of additional surface water required for the environment averages between 3000 and 7600 gigalitres a year. Based on internal analysis, the Murray-Darling Basin Authority (MDBA 2010:XXI) has determined that it would only examine scenarios with reductions of between $3000 \mathrm{GL} / \mathrm{yr}$ and $4000 \mathrm{GL} / \mathrm{yr}$. These reductions in diversions have been met with resistance by irrigators (ABC 2010). Meanwhile, environmental-conservation groups and ecologists have reservations that a volume in the lower end of the range will 
be sufficient to restore ecological character to the Murray-Darling Basin (MDB) (Finlayson 2010). Indeed, the 3000 GL/yr scenario would leave the CondamineBalonne, Gwydir, Loddon, Lower Darling and Murray regions in poor condition (MDBA 2010:74).

In the next phases of finalising the Plan and implementing State water plans, there are significant opportunities to maximise the benefits associated with reallocating water. Key to achieving this objective is the application of the equi-marginal principle of equating marginal benefits associated with reallocating water from one use to another. By utilising the economic-value estimates associated with different uses and ecological modelling, it is possible to approximate the marginal benefits to multiple users across the Basin. While this is a powerful organising principle, it is complex to implement in practice. Even partial implementation of the principle will deliver considerable gains as the exercise requires a concerted effort to understand the complex, dynamic relationships among water quantity and quality and flow regimes necessary to deliver the outcomes. Investments in institutional arrangements and incentives that are compatible with water being put to highest and best use across the Basin will also be required.

The remainder of this chapter is organised around three central challenges in achieving the objective of maximising the economic, social and environmental benefits of the Plan. First, we consider the importance of improving understanding of the economic benefits and positive effects of improved environmental flows. This section also discusses potential approaches to integrating these benefits into a rigorous and transparent benefit-cost decision-making framework to support the policy process. Second, we discuss how the benefit-cost framework must serve multiple purposes, including the evaluation of long-term average allocation trade-offs, temporal and spatial variations in flow, as well as the systemic risks associated with an uncertain future climate. Finally, we outline how the maximisation of net benefits depends on a robust and efficient set of institutional arrangements that combines top-down and bottom-up processes to reconcile competing and complementary goals of different planning elements at the Basin and State levels.

\section{Environmental Benefits}

There have been a number of studies assessing the benefits associated with improving rivers, wetlands, red-gum forests and the Coorong. Hatton MacDonald et al. (2011) and Morrison and Hatton MacDonald (2010) summarise the tourism and recreational benefits, amenity values and the non-use values (bequest, intrinsic and existence values) across the Basin. The body of work 
on benefits can guide decision making in that it provides insight into the relative value of water for different environmental goals, including providing water to ecosystems (for example, waterbird breeding versus fish populations), providing water to different locations (upstream versus downstream) and to different ecological assets. For the Murray River, as an example, if there were a 10 per cent increase in healthy native vegetation, a 15 per cent increase in fish populations, the frequency of waterbird breeding increased by three years, and the number of waterbird and other species increased by 20 per cent and the quality of the Coorong also improved from poor to good, the total increase in non-use value would be an estimated $\$ 7.5$ billion on a 10 -year net present-value basis (Morrison and Hatton MacDonald 2010:31).

Several messages emerge from the non-market valuation literature completed in recent years with respect to the Murray-Darling Basin. In general, values appear to be increasing over time, with more recent studies producing largervalue estimates for a number of attributes. The evidence is compelling but not conclusive. In general, it appears that the values held for the River Murray are much larger than for other rivers in the Basin or Australia (Morrison and Hatton MacDonald 2010). This likely reflects the greater significance of the Murray, environmental education and media attention in recent years. There is some evidence for the iconic status of Murray-based ecological assets: values for fish populations and waterbird breeding were larger for more significant rivers/ wetlands. Similar evidence was found for native vegetation. In contrast, values for providing habitat for waterbirds and other species did not appear to be a function of the type of asset class - that is, bird breeding and bird habitat were important whether the asset was a coastal wetland such as the Coorong or major wetlands such as Barmah-Millewa.

To enable benefit-cost analysis with a more robust consideration of environmental values, a number of challenges remain to be addressed. In particular, there is the choice of appropriate assumptions relating to the geographic extent of preferences of respondents. There might be some spatial variation in willingness to pay when comparing ACT and Victorian responses (Hatton MacDonald et al. In review). ACT survey respondents were willing to pay significantly more, which might be due to differences in environmental preferences. Zander et al. (2010) demonstrate that southern urban residents hold values for lessdeveloped, northern tropical rivers (for example, the Daly, Fitzroy and Mitchell rivers). State-based research of water-based ecological assets reveals intra-state variation in estimated benefits (Bennett et al. 2008; Morrison and Bennett 2004). This might reflect differences in study design, sampling and preferences. There are also valuation differences based on frequency of visitation. Rolfe and Prayaga (2007) find regular visitors have higher values than one-time visitors to freshwater impoundments. 
Another segment of water-based and flow-based values is recreational benefits. Some recreational activities - such as boating and fishing - have developed opportunistically in the Murray-Darling system, capitalising on the regulated flow regimes associated with irrigation (Howard 2008). Recreational boating and fishing on Lake Hume during high summer irrigation flows are examples (Crase and Gillespie 2008). Some of these recreational activities might be adversely impacted by changes in flow regimes, however, any negative effects on these recreation pursuits might be offset by improvements in nature-based recreation that might be enhanced by more natural episodic flooding and drying patterns.

Another challenge lies in quantifying 'dose-response' relationships for changes in flow-that is, estimating the marginal improvement in environmental health per unit of additional flow. Also necessary is an understanding of the relationship between a given level of improvement in environmental health and economic value. This relationship is complicated by non-linearities between improvements in environmental quality and value. Further work in advancing ecological response functions and values associated with marginal improvements is required for effectively guiding public policy.

This body of work provides greater confidence and understanding about a suite of environmental benefits. It also reveals a series of gaps for future science and decision support. First, there are only estimates for a subset of environmental and other positive externality benefits relevant to the Plan and its implementation. There are issues of spatial and temporal coverage including the need for dynamic assessments for periodic trade-offs across multiple uses over the full life cycle of water reform. For example, estimated benefits might inform decisions between upstream and downstream environmental watering. ${ }^{1}$ Flow regimes for healthy floodplain vegetation (for example, red-gum forests) require episodic flooding and drying versus long periods of inundation that occur with river regulation. Further, peak irrigation and municipal summer demand might not coincide with the watering requirements of iconic wetlands. The management of flow patterns to maximise environmental and socioeconomic values will be complex, requiring the application of the best ecological science with socioeconomic assessment. Furthermore, there are real challenges to translating benefit-cost analysis into a decision-support framework that can support the dynamic implementation and adaptive learning at the appropriate spatial and temporal scales as the Plan moves into the implementation phase.

1 There are, however, gaps and uncertainties that would preclude disconnecting assets from the river if guided by the precautionary principle. 


\section{Other Benefits and Multiple Objectives}

There is a long history of investment in the River Murray, without a significant reversal in degradation (Lee and Ancev 2009). Setting the long term SDLs and reestablishing a share of the water for the environment present a rare opportunity to move out of the realm of cost effectiveness in water policy to full benefitcost analysis. In this section, we consider the challenges in providing rigorous hydro-economic modelling, linked with costs and benefits, as a constructive contribution to the implementation of the Plan. A number of non-market valuation studies have been conducted in the Murray-Darling Basin, which can be used as part of the process of setting SDLs and guiding implementation trade-offs. There remain regions of the Basin, however, where no primary data are available. Targeted investment in primary research to fill the gaps will make decision making more robust. It is also recommended that a thorough stocktake and evaluation of costs of the 'do-nothing' alternative be completed. The status quo is one of declining environmental quality. This would serve as a baseline against which potential benefits of the Plan can be compared.

The advantage of the benefit-cost approach is that it involves a systematic consideration of all relevant benefits and costs. As a result, there might be more transparency in the consideration of trade-offs between environmental and economic outcomes. The trade-off between irrigated agriculture and environmental water was highlighted in the Guide to the proposed Basin Plan (MDBA 2010). There are, however, also multiple objectives that will benefit from increased flows intrinsic in the proposed SDLs. These objectives include improving ecosystem health, providing adequate conveyance water, irrigation, recreation, cultural flows for Indigenous people across the regions, water quality and critical human needs. For instance, conveyance water requirements will be met more of the time, reducing the need for investment in pumps and weirs. The dilution effects of more flow should improve water quality and the economic benefits of reduced salinity are considerable for irrigators, water utilities, and urban and rural consumers. More water for the environment could also enhance urban water supply reliability and quality, potentially reducing, or delaying, investments in alternative water supplies. There are considerable challenges in estimating the benefits attributable to the overall volume of environmental water and the timing of its delivery. The goal of maximising multiple objectives requires a detailed ecological and socioeconomic understanding of how these objectives interact.

Many of these interactions are positive. For instance, an environmental watering plan could be designed to take into account the ancillary benefits of specific flow regimes that not only achieve ecological goals but also reduce the incidence of blue-green algae blooms, which compromise habitats and water 
quality. Jackson et al. (2010) make recommendations on how the Basin Plan could be more sensitive to improving Indigenous community benefits. A first step to incorporating Indigenous water values in the implementation of the Basin Plan is to catalogue the spectrum of these benefits in each catchment. A second step is to assess the extent to which they are coincident geographically and temporally with other value streams, such as environmental water. Where these value streams are convergent, there is no trade-off. Where, or when, they diverge, a mechanism - such as a set of rules or incentives for optimising joint benefits or for prioritising one set of values at the catchment or basin-wide level, and for various time slices - needs to be developed. A recommendation of this work is that Indigenous participation in the co-management of environmental water through shared governance arrangements is a potential mechanism to ensure the Basin Plan is 'more inclusive of Indigenous water values, use and priorities' (Jackson et al. 2010:154).

The biophysical modelling underpinning the Plan was based on analysis of flow regimes required for ecological health and water quality across the MDB system. More research is required to understand the full range of impacts on water for conveyance, cultural values, and municipal industrial water issues. A thorough socioeconomic assessment in line with best science and policy practice might provide transparency and accountability in the determination of Plan implementation trade-offs in the pursuit of maximising net total benefits.

\section{Balancing Top-Down and Bottom-Up in Institutional Design of the Plan}

The Water Act 2007 (s. 22, Items 3 and 5) mandates the MDBA to develop strategies, including flexible institutional arrangements, to achieve multiple objectives and address risks associated with interception, climate change and limits to knowledge. These institutional arrangements must 'achieve efficient and cost effective water management and administrative practices' (Water Act 2007, s. 21, ss. 4[b]). The Act explicitly provides a directive for 'adaptive management' (ss. 21, 4[c][i]), which implies an active feedback process to link basin-level planning and State implementation. In this context, once SDLs are set, the Plan will involve a set of discrete elements, recorded in Table 15.1. For each element, the responsible level or levels of government are indicated. This tabulation highlights the interaction among the Commonwealth, the MDBA and the States. 
Table 15.1 Plan implementation elements with responsible party

\begin{tabular}{l|l}
\multicolumn{1}{c|}{ Plan element } & \multicolumn{1}{c}{ Responsible party } \\
\hline Transitional arrangements & Commonwealth \\
\hline Environmental water plan & MDBA and States \\
\hline Water-quality and salinity plans & MDBA and States \\
\hline Critical human needs & MDBA and States \\
\hline $\begin{array}{l}\text { Development of surface and groundwater } \\
\text { water-sharing plans }\end{array}$ & States and MDBA accreditation \\
\hline Conveyance water & MDBA objectives and operator compliance \\
\hline Water-trading rules & MDBA and Australian Competition and \\
\hline Program monitoring and evaluation & MDBA \\
\hline
\end{tabular}

The optimisation of multiple objectives poses significant coordination and governance challenges to the implementation of the Basin Plan. Implementation will require efficiency in institutional and management arrangements to deliver the required regime (as guided by the best science combined with socioeconomic assessment) and to respond to changing circumstances. Three key questions are: first, at what level of government is it best to implement the different aspects of the Plan? Second, is there sufficient institutional capacity to achieve the Basin Plan's targets and goals? Third, how should linkages be structured across different levels of government to maximise net benefits at the local level to the maximum degree consistent with basin-level objectives?

The Water Act 2007 addressed a need for coordination among the States for a whole-of-basin approach. The Guide presents the implementation process as a two-tier system of basin-wide planning followed by State-level integration in water sharing (MDBA 2010:Figure 1.3). Although the MDB Plan has involved significant top-down elements, there are considerable opportunities within the Plan for involving localised institutions. This could add significant value by providing the necessary local knowledge to maximise environmental, cultural and socioeconomic values as well as the flexibility to respond to climatechange impacts on the Basin's resources. Conceptually, as the Plan moves into implementation, coordination will involve more or less of three principal approaches (Garrick et al. 2011).

1. Top-down: centralised implementation of central requirements of the Plan such as SDLs - for example, by detailed directive to infrastructure operators by the MDBA-chaired Basin Environmental Watering Committee.

2. Bottom-up: vest decisions at the State and catchment levels with basin-wide oversight limited to accreditation of State plans. For example, the Plan could be implemented allowing significant autonomy to States in decisions about 
environmental water scheduling with regard to recommendations from the MDBA Basin Environmental Watering Committee.

3. Nested arrangements: this would involve setting the institutional and management arrangements such that the MDBA, the Commonwealth Environmental Water Holder (CEWH), and States have the incentive to plan for and manage the resource adaptively for the environment, while ensuring: a) appropriate capacity for local, field-based expertise; and b) accountability to both local and basin-wide objectives through environmental, waterquality and water resource-sharing plans.

The relative balance of top-down and bottom-up approaches varies by phase of implementation (see Table 15.1); the critical challenge lies in achieving a balance between basin-wide accountability and proper incentives for local ingenuity. This challenge involves balancing the advantages and disadvantages of central versus local (catchment or State) action in each element of the Plan tabulated in Table 15.1.

The transitional arrangements require the development of policy and mechanisms to acquire water efficiently, based on the benefits for the environment and costs to communities detrimentally affected, and the physical constraints on sourcing water to achieve local versus downstream benefits. There might, however, be a role for local communities to have input into the design of transitional arrangements to achieve adjustment in irrigation-based communities with greater efficiency and lower third-party impacts. The advantage of local action lies in knowledge about regional economic productivity, interdependencies and third-party impacts; the MDBA and Commonwealth can provide central oversight to ensure due diligence and accountability in the investments in voluntary buybacks and infrastructure.

The Environmental Water Plan and delivery arrangements require a combination of centrally established criteria and local expert knowledge of time and placespecific information. This could be achieved by enabling and accrediting a set of decentralised environmental water trusts and providing rules and incentives for them to work in a coordinated way with the CEWH (Young 2010). This model allocates a portion of the Commonwealth environmental water holdings to regional trusts and reserves the balance for central management. This approach establishes a nested-governance arrangement that provides incentives for entrepreneurial management and delivery decisions to maximise local environmental outcomes in concert with basin-wide and cross-catchment objectives. The Environmental Water Plan established as a component of the Basin Plan would ensure consistency of State and regional environmental watering decisions by 'specifying overall environmental objectives for the Murray Darling Basin's water dependent ecosystems' (MDBA 2010:162). It would 
also guide development of strategic environmental water plans for each surfacewater resource plan area. Because environmental water delivery will remain with the States, mechanisms for pairing local decisions and priorities with those of the Basin-wide Environmental Watering Advisory Committee will need to be carefully structured. Nested-governance arrangements take advantage of knowledge and capacity to maximise local benefits of the pool of environmental holdings, as well as the ability to adapt to real-time opportunities to adjust environmental water-delivery schedules to achieve desired flow regimes. The MDBA offers the central coordination to ensure proper trade-offs between local and downstream benefits across the States, including the timing and delivery of environmental holdings across State boundaries.

Water quality and salinity plans identify roles for both basin-wide and Statelevel action. Basin salinity management is an area of past success in nested governance (Connor 2008). The Water Quality and Salinity Management Plan will set targets for the Basin-wide water quality for aquatic ecosystems as well as for drinking, recreation and irrigation water. Water-quality issues will require integration into State Water Resource Plans that will be required to incorporate Water Quality Plans to achieve the overarching objectives. Nested arrangements have been successful through technical assistance provided to the States regarding the relative effectiveness and costs of salinity-control options. These information flows link Commonwealth guidelines and capacity building at the State level to achieve water-quality objectives and promote a feedback loop for adaptive learning as States implement plans and projects under the Basin Salinity Management Strategy.

The accreditation process is outlined in the Guide as a nested arrangement that involves federal oversight of State water-sharing plans (MDBA 2010:Figure 12.2). The MDBA will set criteria for accreditation against which the States' surface and groundwater management plans will be evaluated. Approved plans are accredited for 10 years. The MDBA may recommend that a plan not be accredited, in which case the minister may overrule this recommendation or recommend that the MDBA prepare the relevant plan. If the MDBA is directed to prepare a water-resource plan, the minister may approve this plan or direct the MDBA to revise the plan. The accreditation process could be guided explicitly by a full socioeconomic cost-benefit assessment of environmental and cultural benefits.

From an institutional perspective, the objective of maximising net benefits applies in the development of the Plan and its implementation. Implementing the Plan requires basin-wide planning with State-level water-plan integration. The relative balance of top-down and bottom-up approaches could vary by phase of implementation to achieve a balance between basin-wide accountability and incentives to realise and maximise multiple benefits by means of capitalising on 
local incentives and knowledge. Substantial opportunities exist for developing nested institutional arrangements and governance structures that capitalise on local knowledge and expertise, whilst assuring consistency, enforcement and accountability to higher-order institutions.

\section{Conclusions}

This chapter reviewed challenges in achieving the objective of maximising the economic, social and environmental benefits of the Plan. First, we consider the importance of understanding of the economic benefits and positive externalities associated with improved environmental flows. We outlined how to do this by building on existing environmental-benefits economics and by addressing some key gaps, support for plan implementation can be improved.

Second, we outlined how realising maximum net benefits to society - at least implicitly-involves a benefit-cost framework that accounts for multiple objectives and trade-offs, temporal and spatial variations in flow, as well as the systemic risks associated with an uncertain future climate. There are multiple objectives, such as water quality, which improve with the dilution effects of more flow, with benefits of reduced salinity for irrigators, water utilities, and urban and rural consumers. More water for the environment will also enhance urban water supply reliability, reducing, or delaying, investments in alternative water supplies. The goal of maximising multiple objectives of ecosystem health, irrigation, recreation and cultural flows for Indigenous people across the regions, water quality and critical human needs is inherently complex. Continued effort to improve detailed ecological and socioeconomic understanding of how these objectives interact will allow better realisation of improved outcomes in Basin Plan implementation.

Finally, we discussed how the maximisation of net benefits depends on a robust and efficient set of institutional arrangements that combines top-down and bottom-up processes to reconcile competing and complementary goals of different planning elements at the Basin and State levels. From an institutional perspective, the objective of maximising net benefits applies in the development of the Plan and its implementation, including scope for adaptive learning. Substantial opportunities exist for developing nested institutional arrangements and governance structures, which capitalise on local knowledge and expertise, whilst assuring consistency, enforcement and accountability to higher-order institutions. The institutions must be flexible in order to adapt to climate change and the inevitable surprises that result from limits to knowledge.

Ultimately, the process of fully understanding all costs, benefits and tradeoffs will never be complete. Interactive rounds, however, which improve 
the understanding of the costs and benefits, can support and potentially improve decision making. Thus, there is a need for built-in, periodic updates of the evaluation of the trade-offs across multiple uses over the full life cycle of water reform. For example, under reduced rainfall and inflow scenarios, estimated benefits might be required to inform decisions between upstream and downstream environmental watering. The management of flow patterns to maximise environmental and socioeconomic values will be complex, requiring the application of the best ecological science with socioeconomic assessment. Further, the benefit-cost analysis must be slotted into a decision support framework that is dynamic and allows for adaptive learning as the Plan moves into the implementation phase.

The advantage of the benefit-cost approach is that it requires the systematic consideration of all relevant benefits and costs. Even then there will always be limits to our understanding of costs, benefits and trade-offs. Nested-governance arrangements provide coordinated institutional capacity and information flows as a response to an integrated assessment of benefits and costs at a whole-ofbasin scale, over the life cycle of the Plan and with proper feedback between Commonwealth and local levels to promote adaptive learning. Implementing this framework will require updating of the shared understanding of local communities, States and the Commonwealth Government as the Plan is rolled out. This approach could also lead to more transparency in consideration of trade-offs between environmental and economic outcomes and better realisation of multiple objective outcomes.

\section{Bibliography}

Australian Broadcasting Corporation (ABC) 2010, 'Brutal, or bare minimum?: mixed response to Basin Plan', ABC News, 11 October 2010, <http://www. abc.net.au/news/stories/2010/10/11/3034582.htm>

Bennett, J., Dumsday, R., Howell, G., Lloyd, C., Sturgess, N. and Van Raalte, L. 2008, 'The economic value of improved environmental health in Victorian rivers', Australasian Journal of Environmental Management, vol. 15, pp. 13848.

Commonwealth of Australia 2004, Intergovernmental Agreement on a National Water Initiative, Commonwealth of Australia, Canberra, <http://www.nwc. gov.au/resources/documents/Intergovernmental-Agreement-on-a-nationalwater-initiative.pdf $>$

Commonwealth of Australia 2007, Water Act 2007, No. 137 (2007), Department of the Attorney-General, Canberra. 
Basin Futures

Connor, J. 2008, 'The economics of time delayed salinity impact management in the River Murray', Water Resources, vol. 44, <doi:10.1029/2006WR005745>

Connor, J. and Young, M. 2003, Environmental water bank options for the South Australian River Murray, Final Report to SA Department of Water, Land and Biodiversity Conservation, CSIRO Land and Water, Adelaide.

Crase, L. and Gillespie, R. 2008, 'The impact of water quality and water level on the recreation values of Lake Hume', Australasian Journal of Environmental Management, vol. 15, pp. 21-9.

Finlayson, M. 2010, 'Experts respond', Rapid Roundup, Murray-Darling Basin Authority Guide release, Murray-Darling Basin Authority, Canberra, $<$ http://www.aussmc.org/2010/10/rapid-roundup-murray-darling-basinauthority-guide-release- $\%$ e $2 \% 80 \% 93$-experts-respond/>

Garrick, D., Lane-Miller, C. and McCoy, A. (2011), 'Institutional innovations for governing environmental water in the western US', Economic Papers, vol. 30, pp. 1-18.

Hatton MacDonald, D., Morrison, M., Rose, J. and Boyle, K. (In review), 'Valuing a multi-State river: the case of the River Murray', Australian Journal of Agricultural and Resource Economics.

Hatton MacDonald, D., Tapsuwan, S., Albouy, S. and Rimbaud, A. 2011, 'The value of tourism and recreation in the Murray Darling Basin', in L. Crase and S. O'Keefe (eds), Boom and Bust: Water, tourism and recreation in Australia, Earthscan Publications, London.

Howard, J. 2008, 'The future of the Murray River: amenity re-considered?', Geographical Research, vol. 46, pp. 291-302.

Jackson S., B. Moggridge and C. Robinson. 2010. Effects of changes in water availability on Indigenous people of the Murray-Darling Basin: a scoping study. Report to the Murray Darling Basin Authority. June 2010.

Lee, L. and Ancev, T. 2009, 'Two decades of Murray-Darling water management. A river of funding, a trickle of achievement', Agenda, vol. 16, pp. 5-23.

Morrison, M. and Bennett, J. 2004, 'Valuing New South Wales rivers for use in benefit transfer', Australian Journal of Agricultural and Resource Economics, vol. 48, pp. 591-611.

Morrison, M. and Hatton MacDonald, D. 2010, Economic valuation of environmental benefits in the Murray-Darling Basin, A report to the MurrayDarling Basin Authority, Canberra. 
Murray-Darling Basin Authority (MDBA) 2010, Guide to the proposed Basin Plan. Volume 1: Overview, Murray-Darling Basin Authority, Canberra, <http://www.thebasinplan.mdba.gov.au/>

Rolfe, J. and Prayaga, P. 2007, 'Estimating values for recreational fishing at freshwater dams in Queensland', Australian Journal of Agricultural and Resource Economics, vol. 51, pp. 157-74.

Young, M. 2010, Managing Environmental Water. Making decisions about environmental water allocations, Farm Policy Research Institute, Sydney.

Zander, K., Garnett, S. and Straton, A. 2010, 'Trade-offs between development, culture and conservation - willingness to pay for tropical river management among urban Australians', Journal of Environmental Management, <doi:10.1016/j.jenvman.2010.07.012> 